\section{Are we missing atypical bacterial meningitis in the elderly?}

Sir,

Incidence of central nervous system (CNS) infections is increasing in the elderly ${ }^{1}$ and these may present with unusual clinical manifestations, thereby confounding early diagnosis.

A previously well 94 year old woman was admitted with a right hemiparesis. On admission, she was agitated, dehydrated, confused and dysphasic. She was apyrexial with a regular pulse of $100 / \mathrm{min}$ and blood pressure of $90 / 50 \mathrm{mmHg}$. Neurological examination showed a complete right hemiparesis with no evidence of neck stiffness or positive Kernig's sign. Fundoscopy showed no abnormality.

Investigations showed a haemoglobin of $12.3 \mathrm{~g} / \mathrm{dl}$, white cell count of $6.4 \times 10^{9} / 1$ and erythrocyte sedimentation rate (ESR) of $18 \mathrm{~mm}$ in the first hour. Blood culture was negative and skull radiographs did not reveal any fracture.

During her stay in hospital she developed intermittent pyrexia with no apparent focus of infection. Although she initially improved on rehydration, she gradually deteriorated and died 64 hours after admission.

Autopsy revealed the presence of copious pus, evenly spread in the meninges, in addition to a recent infarct on the left cerebral cortex, due to a thrombosis occluding the internal carotid artery. Bacteriological culture of the meninges showed exuberant growth of Streptococcus pneumoniae and the thrombus from the internal carotid was heavily infiltrated with neutrophils.

Early recognition of meningitis is both medically and legally important in all groups of patients irrespective of age. Bacterial meningitis is steadily increasing in the elderly population and it shows a bimodal peak distribution, the first peak occurring in infancy and the second peak during the fifth to eighth decade. ${ }^{2}$ The mortality rate is high in the elderly and one of the major reasons for this is delay in diagnosis. Delays in diagnosis are probably related to the assumption that changes in mental status are due to senility or dementia or even a stroke. ${ }^{3}$

Common clinical practice relies on the absence of neck stiffness or other meningeal signs to rule out meningitis in the healthy adult. The sensitivity and specificity of neck stiffness are unknown although publications convey the impression that this sign is reliable in most, if not all, cases in awake adults, ${ }^{4}$ except those who are too old, unconscious or immunosuppressed. ${ }^{5-7} \mathrm{~A}$ comprehensive literature search failed to reveal any papers on the sensitivity and specificity of meningismus as a diagnostic test or the role of lumbar puncture in patients without definite headache, stiff neck, fever or clear neurological abnormality ${ }^{8,9}$ In one series of meningitis in the elderly, nuchal rigidity was found in $82 \%$ of patients but $89 \%$ of this group also had pronounced mental status changes and $39 \%$ had focal neurological abnormality. ${ }^{10}$

One of the major problems in attaining a correct diagnosis in the elderly is the presence of multiple pathology. Although the majority of patients present with fever, confusion and stiff neck, confusion may be assumed to be secondary to senility, and the stiff neck to cervical arthritis. In such circumstances one would recommend more frequent 'spinal tap' as a prerequisite to exclude meningitis in the elderly.

Although reported incidence of bacterial meningitis in the elderly has risen from $6.6 \%$ to $7.1 \%$ over the last 14 years (1975-1988) (communication with C.D.S.C., Colindale, London), it is difficult to ascertain the actual incidence of pyogenic meningitis in the elderly when it occurs with another cerebral event. It is possible that a significant proportion of bacterial meningitis in the elderly goes unrecognized and untreated in the presence of stroke or dementia. An increased awareness is undoubtedly necessary amongst the clinicians in charge of elderly patients who should endeavour to exclude an underlying treatable, if not curable, condition in association with another cerebrovascular event. It is suggested that cerebrospinal fluid should be analysed in atypical cases of stroke, or when pyrexia develops without an apparent source of infection in an elderly patient with stroke.

K.K. Chakravarty, A.H. Al-Hillawi, C. Scholes, C.J. Durkin Department of Geriatric Medicine, Stoke Mandeville Hospital. Aylesbury, UK.

\section{References}

1. Newton, J.E. \& Witczynski, P.J.G. Meningitis in the elderly. Lancet 1979, ii: $157-158$.

2. Musgrave, T. \& Berk, S.L. Update: infectious diseases in the elderly. Geriatrics 1988, 4: 31-37.

3. Berk, S.L. Bacterial meningitis. In: Gleckman, R.A. \& Gantz, N.M. (eds) Infections in the Elderly. Little Brown \& Co., Boston, Mass, 1983, pp. 235-263.

4. Callahan, M. Fulminant bacterial meningitis without meningeal signs. Ann Emergency Med 1989, 18: 90/151-93/154.

5. McGee, Z.A. \& Kaiser, A.B. Acute meningitis. In: Mandell, G.L., Douglas, R.G. \& Bennett, J.E. (eds) Principles and Practice of Infectious Diseases, 2nd edition. John Wiley \& Sons, New York, 1985, pp. 560-573.

6. Christie, A.B. Acute bacterial and pyogenic meningitis. In Christie, A.B. \& Hoeprich, P.O. (eds) Infectious Diseases: Epidemiology and Clinical Practice, 3rd edition. Churchill Livingstone, New York, 1980, pp 613-668.

7. Sande, M.A. \& Tierney, L.M. Meningitis: Medical Staff Conference, San Francisco General Hospital. West J Med 1984, 140: 433-436.

8. Health and Public Policy Committee, American College of Physicians: The diagnostic spinal tap. Ann Intern Med 1986, 104: 880-885

9. Marton, K.I. \& Gean, A.D. The spinal tap: a new look at an old test. Ann Intern Med 1986, 104: 840-848.

10. Gorse, G.J., Thrupp, L.D. \& Nudleman, K.L. Bacterial meningitis in the elderly. Arch Intern Med 1984, 144: 1603-1607. 